\title{
Centroamérica: paz, desarrollo y democracia versus guerra y militarismo. El reto de los años noventa
}

\author{
Raúl Benitez Manaut*
}

\section{Resumen}

En este ensayo se discute la posibilidad de la paz, tanto a nivel regional como nacional, haciendo énfasis en las posibilidades de continuación del militarismo y la guerra, frente a los logros en la búsqueda de la paz en Nicaragua, El Salvador y Guatemala. Se relaciona el tema de la paz al de la democracia y el desarrollo económico y también se toma en cuenta el ambiente mundial de distensión, tomando como factor decisivo el hecho de que se está recomponiendo la hegemonía de Estados Unidos en la región después de la invasión militar en Panamá y del triunfo electoral de Violeta Chamorro en Nicaragua. Finalmente, se mencionan como los principales retos para los anos noventa el logro de un modelo de desarrollo viable para las economias que supere la situación de pobreza y marginalidad y la consolidación de los sistemas políticos democráticos.

Sociólogo $\theta$ intemacionalista mexicano. Investigador del Centro de Investigaciones Interdisciplinarias on Humanidades (CIIH) de la Universidad Nacional Autónoma de México (UNAM). Investigador asociado del Centro de Investigación y Acción Social (CINAS) de El Salvador. Autor del libro La Teoría Militar y la Guerra Civil en El Salvador, UCA Editores, San Salvador, 1989, y coautor del libro La Paz en Centroamérica. Expediente de Documentos Fundamentales (1979-1989), CIIH-UNAM, México, 1990. 


\section{Introducción}

El conflicto en América Central reviste caracteristicas nuevas en 1990, comparando con la fecha que se declara abierto, hace diez anos, punto de partida de la militarización y la crisis.

Metodológicamente es preciso senalar una doble dinámica del conflicto: la dirección que va de los conflictos nacionales (principalmente en Nicaragua, El Salvador y Guatemala) hacia sus repercusiones regionales, y la inversa, la forma como los factores externos influyen en los conflictos nacionales. Asl, la "crisis centroamericana" es una suma doble de tres conflictos nacionales o un conflicto regional con componentes nacionales distintos.

Tres son las naciones con conflicto interno, pero cinco paises son actores decisivos del conflicto: Nicaragua, EI Salvador, Guatemala, Honduras y Costa Rica. A su vez, cuatro naciones participan como promotoras de la primera propuesta de solución negociada: México, Venezuela, Panamá y Colombia (organizados en el Grupo de Contadora) y dos paises que geopolíticamente tienen gran relevancia en la región también tienen una activa presencia: Estados Unidos y Cuba. Al mismo tiempo, Europa, otros paises de América Latina y la Unión Soviética también inciden en la región, con una fuerza variable y distintas propuestas.

Ași, el conflicto centroamericano es un rompecabezas que va desde lo más particular (las raices internas del conflicto, definidas por la mayoria de los analistas como la gran desigualdad de las sociedades y el autoritarismo político) hasta la repercusión en el escenario mundial.

El conjunto de naciones y regiones (como Europa o América del Sur) mencionados no tienen un sólo comportamiento hacia la región, y los actores más importantes oscilan entre el apoyo a alguna (o algunas) de las partes de forma económica, política o militar, hasta la promoción de propuestas de paz.

Sin duda, el hecho que mas destaca en el comportamiento de la mayoria de los actores es oscilar, de una posición "militar" a aceptar (o promover) soluciones políticas (o sea, de paz). La razón que explica esto es la no viabilidad, después de diez anos, de las soluciones exclusivamente militares (que plantean el triunfo militar sobre el ejército que se combate: FSLN vs Contrarrevolución en Nicaragua; FMLN vs fuerza armada en El Salvador y URNG vs fuerza armada de Guatemala). Además, a nivel intemacional, aunque no existieran abiertas declaraciones de guerra entre los distintos paises, las tensiones siempre fueron muy elevadas, principalmente entre el Ejército Popular San- 
dinista (EPS) de Nicaragua con las fuerzas ammadas de Estados Unidos (sobre todo las estacionadas en Honduras); y entre el EPS y el ejército hondureno.

A nivel internacional, la principal presión militar la ejerció (hecho demostrado con la invasión a Panamá del 20 de diciembre de 1989) Estados Unidos, pues entre 1980 y 1990 mantuvo vigente la posibilidad de invadir Nicaragua o El Salvador. Siempre estuvo presente la disuasión a través de la amenaza de intervención directa. En el caso de que Estados Unidos hubiera declarado la guerra a Nicaragua, ésta muy probablemente habria recibido el respaldo militar de Cuba, con to que el conflicto estuvo en momentos decisivos a punto de ascender a un nivel superior.

Nosotros dividimos el desarrollo del conflicto regional en dos fases:

1) El periodo militarista (1980-1987), consignado por el acelerado crecimiento de las fuerzas armadas de los cinco paises y por la penetración de los "contras" en Nicaragua - respaldados por Estados Unidos-, el crecimiento del ejército guerrillero del FMLN en El Salvador y la generalización de la estrategia de contrainsurgencia en Guatemala. Al mismo tiempo, se consolida la presencia militar de Estados Unidos en Honduras y en menor medida Costa Rica, y el apoyo económico y militar de Cuba y la Unión Soviética a Nicaragua. En este periodo todo los actores buscan la victoria militar sobre su adversario'.

2) El inicio de la paz regional. (1987...). Este perlodo comienza con el compromiso de Esquipulas II, y se basa en el cansancio de la guerra en los cinco paises. Se cobra conciencia en las élites que toman decisiones en la región sobre la necesidad de la urgencia de la paz, y hay crecientes presiones en el seno de la sociedad civil de los cinco paises, para alcanzar la paz. Tanto a nivel regional como nacional se aceleran las medidas para iniciar la distensión ${ }^{2}$.

\section{Radlografía de Centroamérica a fines de los anos ochenta}

Por múltiples acontecimientos que han tenido lugar en la región, en su área adyacente y en el mundo, la crisis centroamericana ha evolucionado en forma positiva en dirección a la resolución de algunos de sus conflictos nacionales más importantes. En éste aspecto destacan los acuerdos de paz de Esquipulas $\|^{3}$. Los primeros logros de Esquipulas II en términos de frenar la carrera armamentista se dan en Nicaragua, a partir de los acuerdos firmados en Sapoá el 23 de marzo de 19884, que son ratificados cada tres meses entre el gobierno 
sandinista y la contrarrevolución durante 1988, y múltiples acuerdos para la desmovilización en los momentos finales del gobierno sandinista (marzo-abril de 1990) y los compromisos en el nuevo gobierno encabezado por Violeta Chamorro. Recientemente (mayo-junio de 1990) se procedió a la desmovilización casi definitiva de la contrarevolución a través del ONUCA (Grupo de la ONU para Centroamérica, responsable de la desmovilización) ${ }^{5}$.

En El Salvador, se han producido siete rondas de conversaciones entre el FMLN y representantes del gobierno: 2 en 1984; 1 en 1987; 2 en 1989 y 2 en $1990^{\circ}$. $Y$ en Guatemala, pals donde la oligarquia militar se considera la más reacia a conversar con la insurgencia, también se han presentado conversaciones'. En estas se han logrado pocos avances, aunque tanto la URNG ${ }^{8}$ como el gobierno han resuelto buscar opciones politicas al conflicto.

Por otro lado, hay un cambio en la actitud de las diferentes potencias hacia la región. En Estados Unidos se observan tanto actitudes totalmemte contrarias a la distensión en el mundo -como la invasión a Panamá-, como propuestas de presionar a fondo al gobierno salvadoreno para que realice una verdadera negociación con el FMLN, debido a la previsible prolongación de la guerra civil. La Unión Soviótica, por su parte, ha dado muestras de apoyo a la distensión, con el cambio en su política exterior, desde que se implementó la Perestroika en 1985, respetando el área de influencia de Estados Unidos y favoreciendo notablemente la negociación en los conflictos internaclonales. Incluso últimamente, la Unión Soviética ha decidido comtinuar otorgando apoyo económico al gobierno de Nicaragua si éste to solicita y en las conversaciones en Washington entre Bush y el Gorbachov se decidió apoyar todas las iniciativas de solución política del conficto. La URSS busca con esto aplicar la misma fórmula de respeto a la voluntad popular y no injerencia en los cambios políticos observados en Europa del Este, y actuar en Centroamérica de forma similar a las negociaciones políticas e internacionales que se dieron en el cono sur de Arica. En las conversaciones la Unión Soviética se opone a soluciones militaristas en los conflictos regionales?.

En este balance de elementos positivos y negativos, todos los actores que tienen presencia en el conflicto, tanto los directamente involucrados como aquellos que actúan de manera intervencionista y los que buscan la reconciliación entre las partes, coinciden en el hecho de que las sombrlas perspectivas de evolución del conflicto que se vishumbraban principalmente entre 1980 y 1987, ha dado luces de cambiar y evolucionar positivamente hacia su solución. 
Es importante tener presente que actualmente la situación de EI Salvador es la más grave (excluyendo del análisis regional a Panamá) de los tres conflictos que tenian una dinámica militar en sentido ascendente entre 1980 y 1986: el guatemalteco, el nicaragūense y el salvadoreno ${ }^{10}$. Este último es el que se proyecta en sus dimensiones más dramáticas en la región, ya que no se vislumbran salidas militares a corto y mediano plazo, y su dimensión militar continua en la dinámica ascendente que se inició en 1980-1981. En el caso guatemalteco, no obstante tampoco se ha presentado la reconciliación nacional entre las fuerzas insurgentes y el gobierno, el nivel de los enfrentamientos militares parece disminuir (o por lo menos no seguir la tendencia ascendente de EI Salvador), y, en Nicaragua, por el esfuerzo gubernamental por cumplir y profundizar en los acuerdos de Esquipulas II, además de la desmovilización militar de los contrarrevolucionarios, el conflicto militar se ha trasladado a la arena política. En el resto de los paises centroamericanos los conflictos tienen una connotación diferente. En Honduras no existe una oposición armada importante, y el conflicto político se inserta en las luchas y movimientos sociales, existiendo un importante movimiento de rechazo a los contrarrevolucionarios y a la presencia militar de Estados Unidos. En Costa Rica, que sin duda es el pais de menor conflicto de la región, hay también rechazo a los contrarrevolucionarios, y paradógicamente, es el pais que obstaculiza uno de los compromisos más importantes de Esquipulas, por la negativa en el Congreso a ratificar la creación del Parlamento Centroamericano. Panamá, que a inicios de la década buscó escapar a la dinámica de la región, insertándose al Grupo de Contadora como pais promotor de la paz desde 1983, vive un agudo conflicto político interno desde 1987 entre sectores nacionalistas y conservadores, donde el componente geopolítico es muy alto, por la cercania de la fecha de entrega del Canal y la zona y el desmantelamiento del Comando Sur. Este conflicto sin duda irá en ascenso y se suma a los ya existentes en la región.

Las luchas geopolíticas y las proyecciones de las potencias con intereses en Centroamérica, asi como las percepciones que en ellas se tiene de la crisis, han variado. Hacia 1979 Estados Unidos no percibe a la revolución en Nicaragua como una amenaza inminente a su seguridad nacional, por to que, al momento del triunfo sandinista, hay una discusión en el seno de las distintas instituciones que tienen capacidad ejecutiva en asuntos externos, discusión que oscila entre la convivencia con el nuevo régimen y su contención". Hacia 1980, esta percepción cambia y se disena la política de "contención activa" del supuesto expansionismo de la revolución nicaragüense. La política de contención 
activa se despliega durante las dos administraciones de Ronald Reagan (1981-1989) teniendo varios periodos: entre 1981 y 1983, se da la construcción del ejército contrarrevolucionario ${ }^{12}$, instalación de la infraestructura militar en Honduras, realización constante de maniobras militares con fines disuasivos, diseno e implementación de la política de contrainsurgencia en El Salvador ${ }^{13}$ y alineamiento del resto de los paises a la estrategia de Estados Unidos. Entre 1984 y 1986 se da el auge del apoyo a los contrarrevolucionarios y a la contrainsurgencia en El Salvador a través de una política bipartidista ${ }^{14}$, esfuerzo que en términos militares se conoce como "guerra de baja intensidad"15. Entre 1987 y 1989 es evidente el fracaso de esta estrategia, por el nivel que alcanzan los conflictos en Nicaragua y El Salvador y sus repercusiones en el resto de los paises. En este periodo, que arranca con el "destape" del conflicto Irán-contra-gate en noviembre de $1986,{ }^{16}$ se dan importantes cambios políticos en los distintos paises (cambios de gobierno en Guatemala y Costa Rica) ${ }^{17}$, donde ya se esbozan acciones que sin ser antagónicas ni contradictorias con los objetivos de largo plazo de Estados Unidos, expresan preocupación por la escalada militar y el probable estallido de conflictos interestatales agudos (principalmente entre Honduras y Nicaragua), razón que explica la firma de los acuerdos de Esquipulas II. A fines de 1988 y los primeros meses de 1989 hay redefiniciones en la política estadounidense, por el cambio de gobierno. En este periodo tres son las grandes preocupaciones de la administración Bush: 1) que la derrota militar de los contrarrevolucionarios no se transforme en un fracaso político (esto explica la continuación de la ayuda, ahora justificada como humanitaria) y puedan insertarse a la vida política de su pais; 2 ) que la situación en EI Salvador no conduzca a una debacle de las fuerzas armadas y el gobierno; y 3) que sea posible evitar la consolidación de las fuerzas nacionalistas en Panamá, para lo cual necesitan presionar y buscar la salida del general Noriega como comandante de las Fuerzas de Defensa y fortalecer a las agnupaciones politicas conservadoras. Este es el objetivo principal invasión militar del 20 de diciembre de 1989, justificando esta acción dentro de la política de lucha contra el narcotráfico en el continente ${ }^{18}$.

Por otra parte, la política de la Unión Soviética en la región también pasa a tener expresiones activas. La Unión Soviética, si bien es mucho más cautelosa que Estados Unidos, apoya económica y militarmente al gobierno sandinista para que este pueda enfrentar la guerra de defensa y pueda sobrellevar la economia. En términos regionales la Unión Soviética ha respaldado al Gnupo de Contadora y en la asistencia brindada a Nicaragua busca no comprometerse a fondo, pues su presencia en Centroamérica y en general América Latina está mediada 
por sus relaciones con Estados Unidos ${ }^{19}$. A partir del ascenso de Mijail Gorbachov como máximo dirigente soviético en 1985, se ha dado un proceso de distensión internacional muy importante, donde la Unión Soviética ha tenido un papel destacado a partir del reconocimiento de su fracaso en Afganistán. Este clima favorable a las negociaciones, si bien no ha repercutido directamente en la region, si ha influido indirectamente, pues a la par se produjeron los acuerdos de Esquipulas. Es importante mencionar también que la política exterior de Gorbachov busca no enfrentar a Estados Unidos, principalmente en su área de influencia -dentro de la cual se encuentra América Central-, a fin de que Estados Unidos no tenga injerencias en asuntos estratégicos de la Unión Soviética, principalmente por el problema de los movimientos separatistas.

La crisis centroamericana también ha sido objeto de acción diplomática de numerosos palses y organizaciones que, sin tener una actitud intervencionista, buscan su resolución, contribuyendo con diversos mecanismos a entrentar aspectos parciales de ella, principalmente a través de la cooperación económica y humanitaria. Es el caso de la mayorla de las naciones europeas, los cuatro paises del Gnupo de Contadora y organismos internacionales corno la Organización de las Naciones Unidas (ONU) y la Organización de Estados Americanos (OEA). En general, se busca fomentar un ambiente propicio para la negociación, tanto internacional (entre las naciones) como interna (entre los gobiernos y los alzados en armas).

\section{II.a) La dimensión mllitar de la crisis}

Centroamérica ocupa un lugar privilegiado de la atención del mundo por la situación bélica existente y el nivel de intensidad que han alcanzado los entrentamientos armados, perjudicando notablemente a la población civil de los países y modificando estructuralmente las economias de los mismos, principalmente en Nicaragua, El Salvador, Guatemala y Honduras. Numerosos sectores de población, sobre todo los que habitan las áreas rurales, han sido afectados. Igualmente, las economias se han convertido en "economias de guerra". Incluso se tiene una depredación ecológica de gran envergadura que obstaculiza la recuperación de la economia -básicamente en las zonas nurales-.

Este factor, el militar, es que le imprime a la crisis centroamericana una especificidad sui generis que lo distingue de otro tipo de conflictos existentes en otras regiones de América Latina, pues tanto la gravedad de la situación económica como situaciones conflictivas en lo político se presentan en la gran mayoria de los paises latinoamericanos. 
No obstante lo anterior, la existencia de movimientos anmados de oposición en El Salvador y Guatemala y la presencia de los contrarrevolucionarios nicaraguenses responde a factores estnucturales en bo polltico y lo económico. En el caso de El Salvador y Guatemala, la cerrazón de la élite oligárquica-militar excluyó de la lucha política legalelectoral (en los contados casos en que ésta existió como forma de wcha politica) a la mayorla de las fuerzas políticas que se ubicaban del centro político a la izquierda, $y$, en el caso nicaragūense, los contrarrevolucionarios son representantes de una potencia extranjera y de una élite política que fue desplazada del poder de manera total en 1979, siendo herederos de la tradición política somocista. En los dos primeros paises los gnupos amados FMLN y URNG son expresión de fuerzas políticas progresistas, en cambio, en el caso nicaragōense, los contrarrevolucionarios son los representantes de los intereses más conservadores del pais e incluso de la región.

La militarización de la región se sostiene en una estrategia de contención disenada por Estados Unidos y aceptada y compartida por las oligarqulas políticas y militares de los distintos palses. Entre 1980 y 1988 Estados Unidos ha invertido en éste esfuerzo 6,513.9 millones de dólares, de los cuáles casi la mitad se destinan sólo a El Salvadorº. Entre asistencia económica y de seguridad tenemos la siguiente información sintetizada: 2292.0 millones de dólares en asistencia económica y 4221.8 en asistencia militar ${ }^{21}$. Las políticas de dotación de asistencia económica, humanitaria y militar continuaron sin cambios en 1989 y 1990. Incluso, para el caso salvadoreno, en el ano fiscal de 1990, se entregan 546 millones de dólares en asistencia económica y 84.6 millones de dólares en asistencia militar ${ }^{22}$. Para Panamá y Nicaragua, se aprueban fondos especiales para reconstrucción económica y ayuda financiera por $\mathbf{8 0 0}$ millones de dólares ${ }^{23}$.

En términos humanitarios, la población de los tres paises que viven conflictos militares es la más afectada. Entre campesinos desplazados, civiles asesinados y muertos totales por causa de los conflictos, se tiene a un contingente demográfico muy elevado en porcentaje en la región (más del $5 \%$ de la población total): medio millón de salvadorenos desplazados de sus lugares de origen, por haberse convertido sus tierras en teatros de operaciones, otro medio millones expulsado del pais, refugiado principalmente en Estados Unidos, Canadá, México, Guatemala, Honduras y Nicaragua. Más de sesenta mil civiles asesinados y aproximadamente 20 mil hombres en armas (tanto de las fuerzas armadas como del FMLN) entre muertos y heridos. En sintesis, los diez anos de guerra han causado en Centroamérica cerca de 2.8 
millones de refugiados y desplazados y aproximadmaente 160,000 muertos ${ }^{24}$.

En Guatemala se tienen a más de cuarenta mil indigenas refugiados en México atendidos por el Alto Comisionado de las Naciones Unidas (ACNUR), que huyeron de sus poblados por la estrategia de tierra arrasada-aldeas estratégicas", implementada por el ejército de su pais entre 1980 y 1986. 200 mil asesinados políticos desde el golpe do Estado de 1954 hasta 1987 (de los cuales entre 30 mil y 50 mil so cometieron entre 1980 y 1987) ${ }^{25}$. En Nicaragua se tienen a 40 mil muertos entre 1978-1979, en la guerra civil que condujo al Frente Sandinista al poder y otros cuarenta mil entre 1981 y 1987 por la guerra librada entre el Ejército Popular Sandinista (EPS) y la contrantevolución $n^{20}$.

En términos económicos, en los tres paises la "economia de guerra" se conforma en la década de los ochenta. En Guatemala el gasto gubemamental pasa del $15 \%$ en 1987 , en El Salvador del $25 \%$ a partir de 1984 y en Nicaragua del $50 \%$ a partir de $1985^{27}$. En términos de hombres en armas, el incremento también es muy acelerado en los tres paises: de 14,300 hombres en armas en 1977 a 49,600 en 1987 en Guatemala ${ }^{28}$; de 15 mil en 1979 a 71 mil en 1987 en El Salvador ${ }^{20}$ y de 2,000 guerrilleros sandinistas en 1979, las fuerzas armadas en Nicaragua tienen a 77 mil hombres en $1987^{30}$. En los tres paises se ha considerado a fuerzas policiacas y paramilitares. A lo anterior se afaden también fenómenos de militarización en Costa Rica y Honduras, que, si bien no alcanzan las dimensiones de los tres paises mencionados por no tener conflictos internos militares, han tenido atteraciones importantes en la conformación cualitativa y cuantitativa de sus fuerzas armadas (en Costa Rica, por no existir ejército, se han militarizado los cuerpos de seguridad y las fuerzas policiacas) ${ }^{31}$. En conjunto, el incremento de los hombres en armas de la región pasa de aproximadamente de 70 mil efectivos militares, policiacos y de seguridad en 1977, antes de que estallara el conflicto, a más de 300 mil en 1987. En esta última cifra se incluyen efectivos de Panamá y Belice. En total la suma asciende en 184,750 efectivos regulares y 111,200 efectivos paramilitares, policiacos y de seguridad ${ }^{32}$; más aproximadamente 30 mil efectivos antigubernamentales: URNG (2,000), FMLN (entre 6,000 y $10,000)$ y contrarrevolucionarios (entre 15 y 20 mil) ${ }^{33}$. A lo anterior hay que agregar a aproximadamente 13 mil efectivos extranjeros, tomando en cuenta los casi 10 mil del Comando Sur de Estados Unidos asentados en Panamá (que aumentaron notablemente durante la invasión militar del 20 de diciembre de 1989), los aesores cubanos en Nicaragua (200) estos han abandonado Nicaragua con el cambio de 
gobiemo-, los efectivos de Estados Unidos en Honduras (de 1,500 a 3,000 ) y El Salvador (150), y los efectivos de Gran Bretana en Belice $(1,800)^{34}$.

Las cifras anteriores dan una idea de la dimensión que adquiere la militarización de la región. Su tendencia ascondente entre 1980 y 1987 y la necesidad de frenarta explica el porque, a pesar de que existen grandes controversias y connatos de enfrentamiento entre los diferentes gobiemos y fuerzas armadas, fue posible que se firmaran los tratados de Esquipulas II en agosto de 19876.

Esta militarización explica también la urgencia que adquirió para muchos paises el buscar su freno, dado el desequilibrio geopolítico y estratégico que se produjo en la subregión de

- la militarización creciente de la lucha política, tanto desde el campo estatal como en el popular;

- un contexto intemacional favorable donde la distensión era el eje por el que se guiaba el sistema intemacional.

Estos factores que se desarrollan en Centroamérica en la segunda mitad de la década de los anos setenta (el económico, el político, el militar y el intemacional) le otorgan a la crisis de la región las connotaciones explosivas que se viven en la actual década.

La crisis, por los anteriores elementos, trasladada el eje del conflicto de lo estructural y político a lo militar. Por ello, al manifestarse como guerra en los tres paises tomados en consideración, el conjunto de las fuerzas politico-militares, tanto las estatales como las opositoras y las fuerzas intemacionales -Estados Unidos- implementan y desarrollan sus estrategias militares buscando que tengan éxito: Estados Unidos intenta, a través de los contrarrevolucionarios, derrocar al gobiemo sandinista, y, en El Salvador, inicia el esfuerzo de contrainsurgencia más importante después de la guerra de Vietnam. A su vez en Honduras desde 1983 emplaza una infraestructura militar que se convierte en la más importante en territorio latinoamericano después de las existentes en Panamá y Puerto Rico. El gobierno salvadoreno tiene como objetivo contener el avance del FMLN y este, a su vez, disena su estrategia militar a fin de intentar la debacle militar y politica del régimen. El gobierno de Nicaragua destina la gran mayorla de sus recursos a la guerra de defensa contra la contrarrevolución. En Guatemala el ejército implementa una ambiciosa campana contrainsurgente y la insurgencia despliega su ofensiva en los primeros anos de la década del ochenta. De estos esfuerzos militares, el único que logra sus objetivos es el empeno sandinista de impedir que los contrarrevolucionarios lograran 
una base social y el EPS pasa a la ofensiva militar decisiva que logra infligir serias derrota a la contrarrevolución. Por el contrario, en Guatemala no se logra el aniquilamiento de la insurgencia, no obstante la correlación de fuerzas militares favorece al ejército, y en EI Salvador se vive la tendencia ascendente de la guerra.

Dado to anterior, en tres de los paises centroamericanos la lucha política se traslada a la esfera militar por la incapacidad de resolverse los antagonismos en ella. Asl, se pasa al axioma de Clausewitz "la guerra es la continuación de la política por otros medios" ${ }^{n} .^{30}$ En los otros paises - Costa Rica, Honduras y Panamá - se agudizan de igual manera los enfrentamientos políticos y en cada uno de ellos se articulan mecanismos para que su situación interna no desemboque en una situación similar a la nicaragūense, salvadorena o guatemalteca. Aqui se despliega un esfuerzo muy importante por Estados Unidos. EI objeto es que Honduras, cuya situación socioeconómica es similar a la de sus vecinos, no caiga en la misma dinámica, y que Costa Rica colabore diplomáticamente en contra de Nicaragua. De igual manera se busca la colaboración militar de ambos en el esfuerzo militar contra ese pais.

Uno de los elementos más sobresalientes en los anos ochenta se da en el terreno político. Se atribuye gran parte del estallido social a las formas de dominación circunscritas al reparto de poder entre las élites militares y las oligarquias de los distintos paises. Por ello se da un gran esfuerzo por Estados Unidos por transformar los sistemas políticos de los paises para que predomine la democracia formal-electoral como forma de rotación de poder ${ }^{30}$. Este elemento se consolida en los antos ochenta y prácticamente en todo el istmo se desarrollan legislaciones que favorecen la lucha electoral. En Honduras se da el cambio de militares a civiles en 1981, en Guatemala en 1986, en El Salvador se conforma en Asamblea Constituyente en 1982, redacta una constitución en 1983 y se elige presidente en 1984. Igualmente el régimen sandinista, tanto por presiones internas como externas, fusiona hegemonia como legitimidad institucional a partir de 1984 con las elecciones presidenciales. El objeto de lo anterior es lograr presentar opciones a lo que se entiende como una polarización de la lucha política, a fin de lograr instalar en el poder (principalmente en El Salvador y Guatemala) a fuerzas políticas capaces de proyectar una idea de legitimidad y que, por lo mismo, puedan disputar la hegemonia de lo político a las fuerzas sociales progresistas. Se asigna este rol de reformas con contrainsurgencia a partido como la Democracia Cristiana ${ }^{40}$.

La lucha política en el curso de la segunda mitad de los anos 
ochenta favorece a las fuerzas de derecha y desplaza en todos los paises a las fuerzas progresistas e incluso de centro. Este fenómeno de ascenso de las fuerzas políticas de derecha es aun inconcluso. Sus logros más importantes son el triunto de ARENA en las elecciones de El Salvador de 1989; el triunfo de la coalición conservadora en Costa Rica en las elecciones presidenciales de febrero de 1990, con la candidatura de Calderón Fournier; el triunfo de Violeta Barrios de Chamorro contra el FSLN en Nicaragua en febrero de 1990; y el ascenso del dirigente del Partido Nacional, Rafael L. Callejas en Honduras tras su triunto en las elecciones de noviembre de 1989. Igualmente, en Guatemala se prevee el ascenso de las fuerzas de derecha en las elecciones presidenciales de fines de 1990, y, en Panamá, la llegada al poder de las fuerzas más conservadoras no se dió en la lucha electoral, sino por medio de la intervención militar de Estados Unidos.

Esta simbiosis de lo político y lo militar, que entre 1979-1980 y 1987 se proyectó a to militar, por las dimensiones que alcanza retorna progresivamente a lo político a partir de la firma del compromiso de Esquipulas II. Asi, las mismas fuerzas que despliegan su esfuerzo en lo militar, buscan la legitimidad en lo político, principalmente en la lucha electoral. Esto explica porque la lucha electoral adquiere gradualmente importancia en paises donde anteriormente fue irrelevante, siendo menospreciada por las élites oligárquicas-militares de EI Salvador, Guatemala y Honduras. También explica el porqué en paises donde to democrático-electoral nunca existió (como en Nicaragua), ahora adquiere una nueva dimensión, tanto de reconquista de la legitimidad y hegemonia perdidas (para el sandinismo), como de lucha por el respaldo de la población (para las fuerzas que apoyan políticamente a Violeta Barrios). Sin embargo, los límites de lo democrático-electoral en paises como Guatemala y El Salvador se encuentran definidos en la representatividad limitada de las fuerzas políticas que participan de la lucha política electoral (circunscrita del centro político a la derecha), dándose el peligro del retorno a la polarización. Por ello, la restauración de la dominación oligárquica, que implica el riesgo de expresar la polaridad existente en lo militar en el juego político, está presente, peligrando la posibilidad de que se consolide la solución de las contradicciones políticas.

Sin duda el caso salvadoreno es el más dramático por el triunfo electoral el 19 de marzo de 1989 del partido de orientación ultraderechista Alianza Republicana Nacionalista (ARENA) ${ }^{14}$. El incremento notable de la represión y el cierre acelerado de los espacios políticos durante la segunda mitad de 1989 fue el preambulo para que también 
la insurgencia presionara al gobiemo demostrando una gran capacidad de fuego en su ofensiva militar iniciada el 11 de noviembre. Por ello, se explica que no obstante que el gobierno de ARENA realizo dos rondas de pláticas con el FMLN en septiembre y octubre de 1989², no se llega a ningún resultado positivo, por lo que el FMLN lanza la mencionada ofensiva y se convierte en la campana militar más importante de la guerra, ocupando parcialmente zonas importantes de la capital del país, San Salvador.

En los seis primeros meses de 1990 se dieron notables avances en los tres paises sumergidos en una larga espiral de violencia: en Guatemala se reanudan las conversaciones entre la URNG y el gobiemo; en el caso salvadoreno también se reinician las conversaciones para alcanzar una negociación, en Ginebra y Caracas ${ }^{43}$ y en Nicaragua, después del ascenso de Chamorro, se logra la casi total desmovilización de los contrarrevolucionarios.

\section{III) Nuevas dimenslones del confillcto en los ańos noventa}

A to largo del ensayo de la realidad regional en Centroamérica, hemos hecho énfasis en la relación existente entre lo político y lo militar, y los momentos donde predomina alguna de las dos variables imponiéndose sobre la otra. También se ha tomado en cuenta la cambiante realidad internacional.

Para nosotros, el momento iniciado en agosto de 1987, donde la politica se impone de manera notoria sobre la guerra, debe ser profundizado principalmente en los casos guatemalteco y salvadoreno. En este último país, que sin duda vive la más dramática situación en la región, se deben incorporar al proceso político el conjunto de las fuerzas existentes, pues, de no darse ello, se agravará la situación de guerra civil y sus efectos negativos sobre la población civil, como la militarización de la economia y las constantes violaciones a los derechos humanos. La prolongación del conflicto salvadoreho repercute en el resto de la región de múltiples formas: acelera la carrera militar entre los ejércitos, es probable que continue el flujo de población desplazada por la guerra o desesperada por la situación económica, además de que es una fuente constante de desequilibrios en el precario balance geopolítico en toda la Cuenca del Caribe.

Un hecho notable es el cambio radical de la política de Estados Unidos hacia la región. Se pasa desde la opción militarista abierta en Panamá, a un empeno notable por que en El Salvador se alcance una solución negociada (o sea, sin la aniquilación del FMLN, premisa que fue el eje del discurso de Estados Unidos y aceptando ahora su par- 
ticipación como fuerza política). Es probable que este cambio se deba a la percepción de que la guerrilla en ese pais es indestructible en términos militares en esto influyó decisivamente la demostración militar del FMLN en la ofensiva de noviembre de 1989-, por to que buscar que la correlación de fuerzas cambie militarmente a favor del gobierno a través de la asistencia económica y militar es un esfuerzo inútil, que propicia la prolongación del conflicto. En términos del Departamento de Estado "En El Salvador, creemos que este (1990) es el ano del fin de la guerra a través de un acuerdo y negociación donde esté garantizado el espacio político para todos los salvadorenos. (...) En suma, los avances de Estados Unidos son claros: hemos realizado notables esfuerzos bilaterales y multilaterales, y ahora son visibles los logros en favor de la paz alrededor del mundo".4

De igual manera, el hecho de que en Nicaragua el resultado de las elecciones pasadas favorece a Estados Unidos, y que en Guatemala la guerrilla no tiene gran capacidad militar, por lo que su insersión como fuerza política no implica grandes sacrificios, hace que la región tenga perspectivas más promisorias para los anos noventa.

A to anterior hay que incorporar el cambio importante que en el mundo se da hacia la distensión entre las superpotencias y la resolución de los conflictos regionales por medios pacíficos y negociados, por lo que Centroamérica no puede continuar siendo un reducto de la época de la segunda guerra fria. Incluso en la actualidad se afirma que el fin del conflicto bipolar Estados Unidos-Unión Soviética es también el fin de la competencia hegemónica en términos militares y zonas de influencia, siendo sustituida la competencia de las grandes potencias por la hegemonia económica. Por ello, ahora se transforma la tradicional geopolítica y se redefinen los espacios de influencia de los grandes paises.

Con seguridad, el debate sobre el futuro de Centroamérica se da ahora en las posibilidades de nuevos modelos de desarrollo, que sustituyan a los esquemas militarizados y que se basen en el restablecimiento del crecimiento económico, la integración regional, a través de la reactivación de la inversión y el consumo. Al respecto, las nuevas interpretaciones que se han escrito sobre el futuro de la región se basan en volver a darle énfasis al problema del desarrollo y la discusión sobre los diferentes modelos de crecimiento y los requerimientos de estos ${ }^{45}$.

Sobre el futuro de la región, aunque no se observa con éxito la implantación del modelo exportador -con la excepción de Costa Rica-., ${ }^{40}$ si se habla de las nuevas pautas en la que se sostendrá el 
que se logre un rumbo positivo para el despegue de las economias. Un factor importante que se encuentra determinando lo anterior es la crisis de los modelos "estatistas" en el mundo, que en la región se demostró con la no viabilidad del proyecto de economia mixta que se intentó poner en práctica en Nicaragua, buscándose las opciones en modelos alternativos en el esquema de "economias de mercado". Por ello, además de que está aún pendiente el logro de la paz duradera, los grandes retos de la región siguen siendo la construcción (y consolidación) de la democracia y el que se logre instaurar un modelo alternativo de sistema económico que enfrente los grandes retos de la pobreza, marginalidad y subdesarrollo de la región $n^{47}$.

\section{NOTAS:}

1) Ver: Raúl Benitez Manaut "La militarización de Centroamérica problemas de interpretación", Polémica, № 21, San José de Costa Rica, septiembrediciembre de 1986; y Raúl Benltez Manaut "La guerra en Centroamérica: dinámica del proceso de militarización y tendencias" en Sintesis, Núm. 7. AIETI, Madrid, enero-abril de 1989.

2) Ver Ricardo Córdova y Raúl Benfitez Manaut (Comps.) La Paz en Centroamérica: Expediente de documentos fundamentales 1979-1989, CIIH-UNAM, México, 1989.

3) "Procedimiento para Establecer la Paz Firme y duradera en Centroamérica" (Esquipulas II), Guatemala, 7 de agosto de 1987. Documento firmado por los mandatarios de Guatemala, Honduras, Nicaragua, Costa Rica y El Salvador en La Paz en Centroamérica: Expediente de documentos fundamentales 1979-1989, op. cit., pp. 340 a 347

4) "Acuerdo entre el gobierno constitucional de Nicaragua y la Resistencia nicaragüense, Sapoá, Nicaragua, 23 de marzo de 1988. En La Paz en Centroamérica: Expediente de documentos fundamentales (1979-1989), op. cit., pp. 243-245.

5) Hasta el 10 de junio de 1990, ONUCA reporta 11,228 contrarrevolucionarios que se han desarmado en el interior de Nicaragua, se mencioná igualmente que faltan 3,000 por desarmarse, y que el calendario de desmovilización estima que a fines de junio de 1990 estará completo el proceso. La Jornada, México, 12 de junio de 1990, p. 21.

6) Las conversaciones de paz en El Salvador son las siguientes: 1) La Palma, Chalatenango, 15 de octubre de 1984; 2) Ayagualo, La Libertad, 30 de noviembre de 1984; 3) 4-5 de octubre de 1987, San Salvador; 4) México 14-15 de septiembre de 1989; 5) San José, 16-17 de octubre de 1989; 6) Ginebra, 4 de abril de 1990 y 7) Caracas, 19-20-21 de mayo de 1990. En esta última reunión se avanza notablemente en la elaboración de una "agenda" para la negociación. Ver FMLN-Gobierno de El Salvador "Agenda para la negociación", Caracas, 21 de mayo de 1990.

7) Las conversaciones de paz en Guatemala se inician en octubre de 1987. 
Estos son poco frecuentes. Hay otra reunión entre la URNG y el gobierno en Oslo en mayo de 1990.

8) Unión Revolucionaria Nacional de Guatemala. Agrupa a las cuatro organizaciones guerrilleras existentes en el pals.

9) Ver Excolsior, México, 1 de marzo de 1990, pp. 1 y 30.

10) Ver: Raúl Benitez Manaut La teorla militar y la guerra civil on El Savador. UCA Editores, San Salvador, 1989; y Varios, El Salvador: guerra, polficica y paz (1979-1988), CINAS, San Salvador, 1988.

11) Jorge Lawton "Crisis de la hegemonla. La polltica de Carter hacia Nicaragua: 1977-1979", on CIDE, Estados Unidos. Perspectiva latinoamericana. Cuadernos semestrales, N 6, segundo semestre de 1979, México.

12) Ver Lilia Bermúdez y Raúl Benltez Manaut "Los 'combatientes de la libertad' y la guerra de baja intensidad contra Nicaragua", en CIDE Estados Unidos. Perspectiva latinoamericana. Cuadernos Semestrales, Ne 18, Segundo semestre de 1985, México.

13) Bacevhic, A. J., James Hallums, Richard White y Thomas Young "American Military Policy and the Lessons Learned from EI Salvador". The John F. Kennedy School of Government, March 1988. Ver también Max Manwaring y Court Prisk El Salvador at War. An Oral History. National Defense University Press, Washington, 1988.

14) El enfoque bipartidista se concretiza con el Informe Kissinger: Report of the National Biparetisan Commission on Central Amorica Washington. jan. 1984.

15) Lilia Bermúdez Guerra de baja intensidad. Reagan contra Centroamérica, Siglo XXI, México, 1987.

16) Bob Woodward Las guerras secretas de la ClA, Grijalvo, México, 1988.

17) En Guatemala sube Vinicio Cerezo en enero de 1986 y en Costa Rica to hace Oscar Arias el mes de mayo. Estos cambios de gobierno son importantes pues Cerezo es el primer presidente civil en Guatemala que tiene cierta independencia de la élite militar desde el golpe de Estado de 1954 y, en el caso de Arias, busca no comprometer a su país en la militarización regional y se deslinda de las acciones de su antecesor Luis A. Monge, quien colaboró incluso militarmente con Estados Unidos contra Nicaragua.

18) U.S. Department of State Panamá: A Just Cause, Current Policy Ne 1240, Washington, 1990.

19) Ver: Boris Yopo "La asistencia militar soviética a Cuba y Nicaragua 19801984: notas para una discusión", y Rubén Berrios "Relaciones económicas entre Nicaragua y los paises socialistas", en Augusto Varas (Editor) America Latina y la Unión Soviética: una nueva relación, FLACSO-RIAL, Buenos Aires, 1987.

20) Tomado de: Richard Fagen Forging Peace. The Challenge of Central America, a PACCA Book, Basil Blackwell, N.Y., 1987, pp. 147-149.

21). Idem.

22) U.S. General Acoounting Office (Fact Sheet for the Honorable Edward M. Kennedy, U.S. Senate EI Salvador. Pipeline of U.S. Military and Economic Aid, Washington, Feb. 1990. 
23) Para el caso panameho, ver U.S. Foreign Policy Priorities FY 1991 Budget Request, U.S. Departament of States, Current Policy N2 1245. Washington, Feb 1990.

24) Edelberto Torres-Rivas "América Central y los desaflos hacia el fin del milenio", en Edelberto Torres-Rivas (Coord.) América Central hacia el 2000, Nueva Sociedad, Caracas, 1989, p. 14.

25) Americas Watch Committeo Guatemala A Nation of Prissioners, Now York, 1984, y "Memorando al gobiemo de Guatemala sobre una misión de Amnistla Internacional en abril de 1985", en Polémica, separata, San José, 1985.

26) Nicaragua: el impacto de la mutación politica, Cuadernos e informes de la CEPAL, Ne 1, CEPAL, Santiago de Chile, 1981.

27) Ver: CEPAL Controamérica, La evolución de la economla on 1987 CEPALMEX, Doc. 88-9-154, México, 7 de septiembre de 1988.

28) International Institute for Strategic Studies The Military Balance 19771978, London, 1977, y The Military Balance 1987-1988, London, 1987.

29) Cifras gubernamentales y también proporcionadas por la inteligencia de Estados Unidos, ver Department of State, El Salvador. Revolution or Relorm?. Current Policy Ne 546, Wa. Feb. de 1984, p. 7.

30) The Military Balance 1987-1988, op. cit.

31) Esto lo hemos profundizado en Raúl Benitez Manaut "La militarización de Centroamérica-problemas de interpretación", Polémica, Ne 21, San José de Costa Rica, dic. de 1986.

32) Estas cifras están tomadas de la misma fuente para evitar confusiones. La información proviene de los anuarios del International Institute for Strategic Studies The military Balance.

33) Idem.

34) Idem.

35) Un análisis global del proceso de militarización se encuentra en el libro de Gabriel Aguilera El fusil y el olivo. La cuestión militar en Centroamérica, FLACSO-DEl, San José, 1989.

36) Las primeras propuestas de paz fueron esbozadas por Panamá en mayo de 1981, y México y Francia en agosto de 1981.

37) Ver: Raúl Benitez Manaut y Ricardo Córdova M. México en Centroamérica Expediente de documentos fundamentales (1979-1986), CIIH-UNAM, México, 1989, pp. 195 a 268.

38) Esto lo hemos analizado en Raúl Benitez Manaut "El pensamiento militar de Clausewitz", Revista Mexicana de Ciencias Politicas y Sociales, Ne 126, UNAM, México, oct. -dic. de 1986.

39) Informe Kissinger, op. cit.

40) Un análisis profundo de los sistemas politicos en Centroamérica en los años ochenta se encuentra en Edelberto Torres-Rivas Centroamérica: la democracia posible, FLACSO-EDUCA, San José, 1987.

41) Gabriel Gaspar El Salvador: el ascenso de la nueva derecha, CINAS, San Salvador, 1989.

42) Ver "Propuesta del FMLN para lograr la democratización, el cese de 
hostilidedes y la paz Justa y duradera en El Salvador, 11 de septiembre de 1989"; "Acuerdo de México" (FMLN-Gobiemo de El Salvador), 15 de septiembre de 1989; y "Proposición del gobierno de la República para lograr la paz, consolidar la democracia en el pals y reunificar a la sociedad salvadoreha", on La Paz en Contraamérica: Expediente de Documenios Fundamentales (1979-1989), op. cit., pp. 169-175.

43) "EI FMLN ante la reunión de Caracas", Caracas, 21 de mayo de 1990 y "Agenda para la negociación" (FMLN-Gobiemo de El Salvador), Caracas, 21 de mayo de 1990.

44) U.S. Foreign Policy Priorities FY 1991 Budget Request, op. cit., p. 5.

45) Ver William Ascher y Ann Hubbard (Editores) Recuperación y desarrollo de Centroamérica, (Ensayos del Grupo Especial do Estudios do la Comisión Internacional para la Recuperación y el Desarrollo de Centroamérica), Duke University, San José de Costa Rica, 1989.

46) Ver Wim Peluspessy (Editor) La economla agroexportadora en Centroamérica. Crecimiento y adversidad, FLACSO, San José, 1989.

47) Pobreza, conflicto y esperanza: un momento crítico para Centroamérica, (Informe de la Comisión Internacional para la Recuperación y el Desarrollo de Centroamérica), Duke University, San José de Costa Rica, 1989. 